Cite this: Nanoscale, 2014, 6, 4012

\title{
From single crystal surfaces to single atoms: investigating active sites in electrocatalysis
}

\author{
Anthony P. O'Mullane
}

Electrocatalytic processes will undoubtedly be at the heart of energising future transportation and technology with the added importance of being able to create the necessary fuels required to do so in an environmentally friendly and cost effective manner. For this to be successful two almost mutually exclusive surface properties need to be reconciled, namely producing highly active/reactive surface sites that exhibit long term stability. This article reviews the various approaches which have been undertaken to study the elusive nature of these active sites on metal surfaces which are considered as adatoms or clusters of adatoms with low coordination number. This includes the pioneering studies at extended well defined stepped single crystal surfaces using cyclic voltammetry up to the highly sophisticated in situ electrochemical imaging techniques used to study chemically synthesised nanomaterials. By combining the information attained from single crystal surfaces, individual nanoparticles of defined size and shape, density functional theory calculations and new concepts such as mesoporous multimetallic thin films and single atom electrocatalysts new insights into the design and fabrication of materials with highly active but stable active sites can be achieved. The area of electrocatalysis is therefore not only a fascinating and exciting field in terms of realistic technological and economical benefits but also from the fundamental understanding that can be acquired by studying such an array of interesting materials.

Received 22nd January 2014 Accepted 21st February 2014

DOI: $10.1039 / c 4 n r 00419 a$

www.rsc.org/nanoscale

\section{Introduction}

School of Chemistry, Physics and Mechanical Engineering, Queensland University of Technology, GPO Box 2434, Brisbane, QLD 4001, Australia. E-mail: anthony. omullane@qut.edu.au

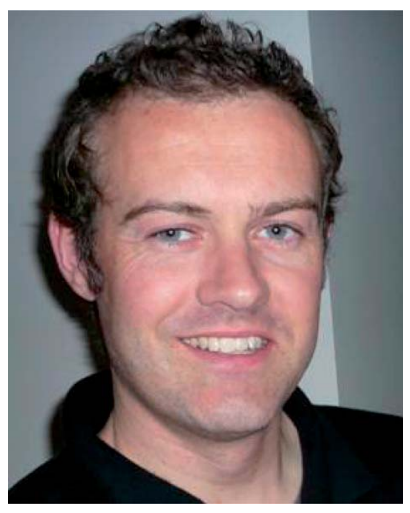

Dr Anthony O'Mullane is an Australian Research Council Future Fellow and Senior Lecturer at Queensland University of Technology (Australia). He received his $P h D$ degree (2001) from University College Cork (Ireland) and completed postdoctoral fellowships at Technische Universitat Darmstadt (Germany), the University of Warwick (UK), and Monash University (Australia). He previously held a position (2008) at RMIT University (Australia) until moving to QUT in 2013. He is currently Chair of the Electrochemistry Division of the Royal Australian Chemical Institute. Dr O'Mullane's research interests are the electrochemical synthesis and characterisation of nanostructured materials; electrocatalysis; catalysis; semi-conducting charge transfer complexes; Li batteries; and the application of electrochemical methods to various aspects of physical, chemical and biological science.

The field of electrocatalysis has recently undergone a significant resurgence in research activity. This is due to several factors including the urgent need to energise future technologies and transportation ${ }^{1-4}$ in a clean and sustainable manner, developing cheap and reliable sensing devices, ${ }^{5-9} \mathrm{CO}_{2}$ conversion into useful products ${ }^{10-12}$ and the fascinating fundamental insights into chemical and material science that this field offers. The ability to chemically and electrochemically synthesise a vast array of nanomaterials with excellent control over shape, size and composition has also been a major impetus in expanding this research area. The initial and continuing studies on single crystal surfaces have provided significant fundamental insight into the role of exposed structural facets on electrocatalytic activity which is a crucial first step to understanding the activity of a plethora of nanomaterials. This in combination with ever more powerful density functional theory (DFT) calculations to predict electrocatalytic activity is unifying the field from studies on near perfect single crystal surfaces to the significantly more complex catalysts used in applications such as fuel cells. However there still remains significant challenges and predicting the activity of a potentially commercially employed catalyst where there are a myriad of parameters to consider such as the role of the support material, composition (bimetallic or even trimetallic systems), structural effects, influence of size, electrolyte and presence of defects ensures that research into 
electrocatalytic processes will remain a fascinating research area.

It should be noted that electrocatalysis is a wide ranging topic that includes catalysis mediated by a redox active species either in solution or immobilised on an electrode surface as well as heterogeneous catalysis at solid electrode surfaces. However in this article it is the latter that will be discussed. A recent book on electrocatalysis in fuel cells highlights both the role of low Pt loadings and the many molecular and non-metal based systems that have the potential to be used in this technology such as conducting polymers, metal macrocyclics and transition metal chalcogenides to name but a few. ${ }^{4}$ The replacement of precious metals such as Pt and Pd for fuel cell applications is highly important for future application but at present the precious metals are still the catalysts of choice. Therefore in this article a focus on metallic systems in particular will be presented not only because of this practical viewpoint but also the interesting fundamental physical chemistry that is discovered in studying these systems.

There have been many reports on factors that influence electrocatalytic reaction rates such as crystallographic orientation of low index plane single crystal surfaces, ${ }^{13-18}$ size $^{19-24}$ and shape $\mathrm{e}^{25-30}$ effects of chemically synthesised nanomaterials, and bimetallic composition. ${ }^{31-46}$ In the majority of cases the presence of defect or active sites is postulated and often considered to be adatoms or clusters of adatoms with low co-ordination number which contribute significantly to increased reaction rates. However the characterisation of these surface states is notoriously difficult due their estimated low coverage, small size and tendency to coarsen under electrochemical conditions. Therefore in this article, studies of these elusive sites is presented from defect rich single crystal extended surfaces to single atom electrocatalysts detailing the established and new sophisticated electrochemical and surface science techniques that are used for their characterisation and visualisation.

\section{Electrochemical characterisation of active site behaviour}

\subsection{Single crystal studies}

Single crystal surfaces have played a major role in understanding structure-activity relationships. Since the discovery by Clavilier, ${ }^{47,48}$ who used a flame melting method to produce high quality surfaces, there have been many studies undertaken with single crystals such as $\mathrm{Pt}, \mathrm{Au}, \mathrm{Ag}$ and $\mathrm{Pd}$ to understand the electrocatalytic activity of different exposed facets such as the low index planes (100), (111) and (110). This has provided significant insights into the design of nanoparticles with the appropriate shape to facilitate the maximum electrocatalytic reaction rate while simultaneously achieving the high surface area required for practical applications. However extrapolation of the reaction mechanisms determined at single crystal surfaces to chemically synthesised nanomaterials is not an easy task and the shape dependent influence of electrocatalytic activity is still a difficult area given the complications that arise from the many defects present at nanoparticles, residual capping agents, propensity for electrodissolution under harsh conditions and surface reconstruction under potential control. Many important reactions have been studied at single crystal surfaces, in particular the oxygen reduction reaction (ORR), hydrogen evolution reaction (HER), methanol, ethanol and formic acid oxidation reactions. In the majority of cases structural sensitivity is observed which differs depending on the reaction of interest, the metal and composition of the supporting electrolyte. There have been many excellent reviews of the topic to which the reader is directed..$^{14-16,26,36,49}$ Of interest in this article are the many studies that have also been undertaken where defects have been introduced into well-defined surfaces in the form of steps, kinks and ledges ${ }^{50,51}$ upon which electrocatalytic reactions are almost universally agreed to be enhanced due to the presence of atoms with low lattice coordination numbers. Generally experiments are undertaken within the stereographic triangle as illustrated in Fig. 1 for the face centred cubic (fcc) metals.

Studying these systems is a step closer to understanding the structure-activity relationships observed at nanomaterials of different shape. Recently Koper has extensively reviewed this topic where it was concluded that step defects, corners of islands, and kink sites are the most active and of the low index planes the (110) facet is usually the most active for many fuel cell relevant electrocatalytic reactions. However there are exceptions and details into reactions preferred at (111) and (100) terraces are outlined. ${ }^{15}$

As mentioned above it is generally agreed that the presence of defect sites is critical to the increased activity of any electrocatalyst. Under extremely clean surface and solution conditions, characteristic electrochemical signatures associated with the high index planes of metals in the stereographical triangle presented in Fig. 1 can be observed. Hamelin was a pioneer of this work at both low $^{53}$ and high index surfaces and a typical example of the latter is that for gold where cyclic voltammograms were recorded in perchloric acid. ${ }^{54}$ This electrolyte was chosen to avoid adsorption effects as encountered with sulphate ions which obscure the fine detail observed in the double layer region. In this case a high index plane is defined as being

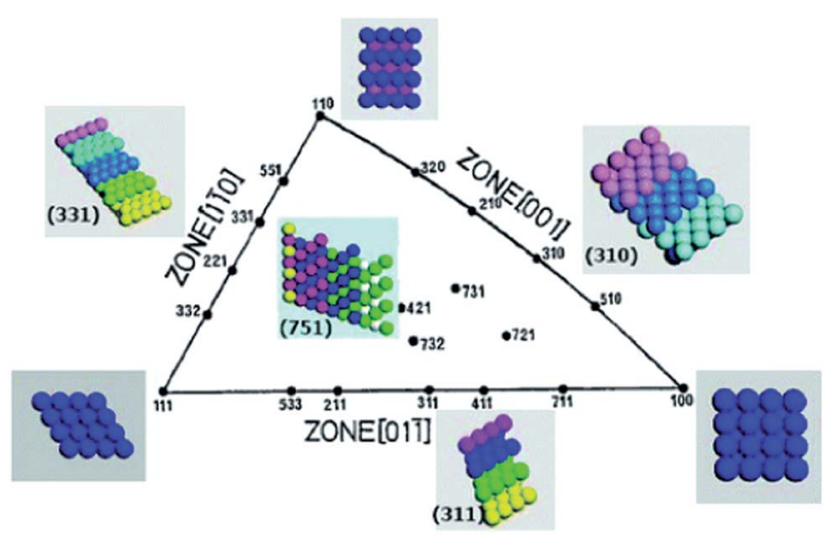

Fig. 1 Unit stereographical triangle of fcc single-crystal surfaces and the corresponding models of surface atomic arrangements. Reprinted from ref. 52 with permission of the Royal Society of Chemistry. 
greater than $5^{\circ}$ from a low index face which are regarded as stepped and open faces. Fig. 2 shows cyclic voltammograms recorded at the (311), (310) and (554) facets.

It is quite clear that different high index planes have unique voltammetric signatures in the double layer region and the oxide formation and reduction regions (Fig. 2). Through this approach it can also be readily identified which surfaces undergo surface reconstruction by varying the potential limits of the voltammetric scan. A significant amount of detail is contained within the double layer region of these surfaces and offers a unique electrochemical fingerprint of a highly stepped surface which can be correlated with scanning tunnelling microscopy (STM) experiments. ${ }^{55}$ More recently Feliu investigated stepped Pt surfaces for the $n(111)-(100)$ and $n(100)-(111)$ systems (where $n=$ number of atomic rows) of the stereographical triangle in a similar manner in both perchloric and sulphuric acid where distinctly different hydrogen adsorption/ desorption and oxide formation/reduction regions were observed on the different surfaces. This allowed structural information to be correlated with activity for the ORR ${ }^{56,57}$ Hoshi et al. extended such a study to investigate the $n(111)-(111)$, $n(111)-(100), \quad n(100)-111)$ and $n(100)-(110)$ systems in perchloric acid where they reported that the active sites for the ORR are the on-top, bridged, or three-fold hollow sites that are located between the (111) terrace edge and the (111) terrace

(a)

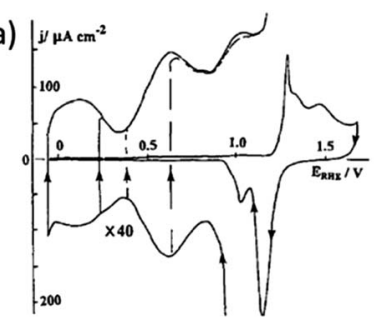

(b)

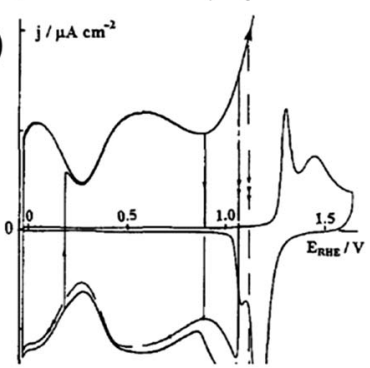

(c)

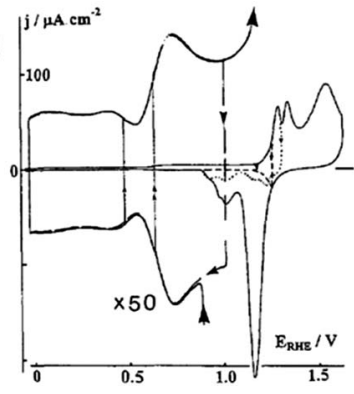

Fig. 2 Cyclic voltammograms recorded for high index planes of gold single crystals in perchloric acid (a) (311), (b) (310) and (c) (554). Adapted from Fig. 4, 9 and 11 ref. 54 with permission of Elsevier. atomic row neighbouring to the edge. ${ }^{50}$ These studies illustrate the ability of electrochemical characterisation in a blank electrolyte to determine the nature of active sites that are responsible for electrocatalytic reactions.

In the studies just described obtaining quantitative information about specific surface sites is problematic, in particular for platinum, where hydrogen and anion adsorption take place on different surface sites in a similar potential range. Also, the contribution from (111) sites for instance is spread across a large potential range rather than a single peak which makes the individual contribution of (111) sites difficult to obtain. Feliu et al. addressed this by demonstrating that bismuth, and germanium adsorbed on platinum electrodes through a spontaneous deposition approach can be used as probes to characterise specific domains present on the surface of $\mathrm{Pt}$ single crystal electrode. ${ }^{58}$ The advantage of this approach is that it is performed in situ under the typical conditions that the electrocatalyst will be utilised. Electrochemical desorption of $\mathrm{Bi}$ is shown in Fig. 3a where it is immediately apparent that the hydrogen adsorption region is completely suppressed and a well-defined stripping process at $0.62 \mathrm{~V}$ is observed attributed to (111) terrace sites (note the sharp peak in blank electrolyte at $0.26 \mathrm{~V}$ is attributed to steps on the (111) terraces).

The magnitude of the peak decreases as the step density increases. By using the $\mathrm{Pt}$ (111) response and that recorded at the stepped surfaces, calibration plots between the charge density measured under the adatom redox peak, specific for the type of surface site, and the corresponding terrace size were obtained. For the case of germanium the hydrogen adsorption region is again suppressed and a clear oxidation process is observed above $0.40 \mathrm{~V}$ which involved almost all sites in the (100) ordered domains. Analogous calibration plots were
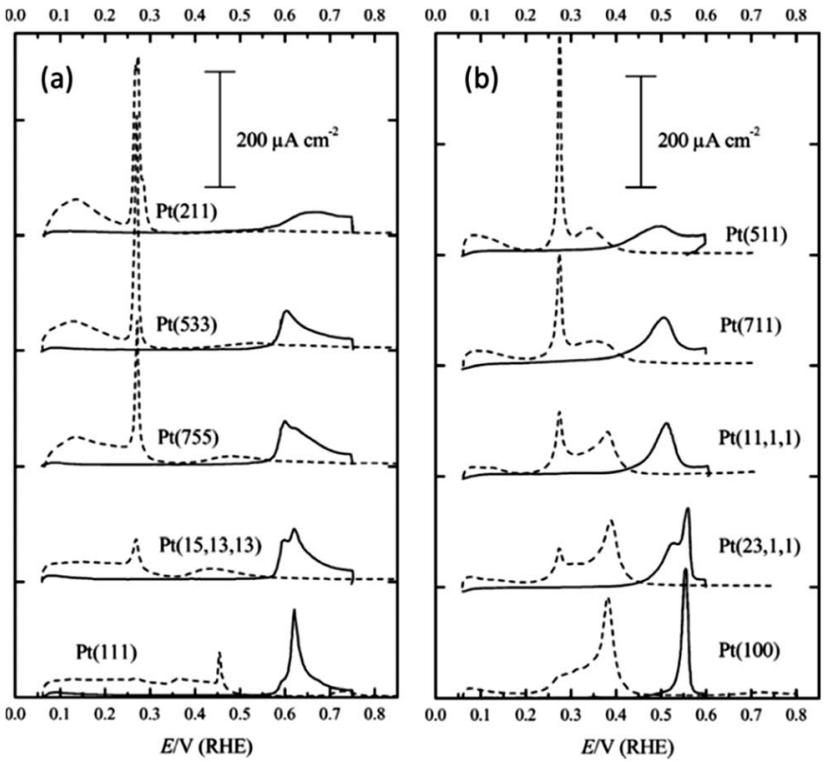

Fig. 3 Voltammetric profiles of Pt single crystal electrodes with irreversible adsorbed (a) bismuth and (b) germanium recorded in $0.5 \mathrm{M}$ $\mathrm{H}_{2} \mathrm{SO}_{4}$. Adapted from Fig. 1 and 3 in ref. 58 with permission of the Royal Society of Chemistry. 
achieved and from analysing the slope of the plot it was concluded that the germanium contribution came from the (100) terrace sites and not the (100) step sites. With these probes the fraction of (100) and (111) ordered domains on nanoparticle samples was identified which agreed with data obtained using deconvoluted voltammograms recorded in the hydrogen adsorption/desorption region. This approach was recently extended by Angelopoulos et al. ${ }^{59}$ who also used $\mathrm{Bi}$ and Ge stripping experiments to determine contributions from (111) and (100) terrace sites and hydrogen desorption studies to determine the contributions from stepped (110) sites and low co-ordination sites at Pt nanoparticles. This structural information was then correlated with activity for the ORR and it was found that the surface active site distribution was dominated by contributions from 5-coordinate sites on stepped surfaces like (110) and (311), as well as low-coordination edge and vertex sites thereby providing new insights into the source of mass activity variation seen for nanoparticle catalysts for this reaction. Finally CO stripping experiments have been extensively used to characterise single crystal surfaces which is highly sensitive to surface structure and has been utilised by many laboratories. This is an invaluable method for characterising surface sites and has recently been reviewed in considerable detail by Koper ${ }^{15}$ and therefore will not be included in this article.

\subsection{Polycrystalline samples}

Although single crystal surfaces provide significant fundamental insights into electrocatalytic reactions they are generally not practical in working devices. In particular the high index planes of metals are costly, have low surface area and reconstruct under normal operating conditions. ${ }^{\mathbf{5 1}}$ Therefore there has also been a significant research effort in understanding the electrochemical behaviour of metals in the form of bulk electrodes, electrodeposited nanostructures and chemically synthesised nanomaterials. In an analogous manner to electrochemical measurements undertaken at single crystal surfaces in supporting electrolytes many studies have been undertaken at the polycrystalline samples just mentioned. This is not only important from an electrocatalytic point of view but is also important in determining the cleanliness of a surface. A particularly interesting aspect of this work was introduced by Burke $^{60}$ who observed unusual cyclic voltammetric behaviour at a variety of metals in acidic, alkaline and neutral media whereby significant responses were observed in the double layer region of metals which in most cases is assumed to be simply associated with capacitive charging current. The term "premonolayer oxidation" was coined to describe such phenomena and attributed to the oxidation of active sites on metal surfaces. The active site $\left(\mathrm{M}^{*}\right)$ was postulated to consist of metal atoms or clusters of atoms with low co-ordination number in a metastable state that were prone to oxidation at potentials lower than that for their bulk or equilibrated surface state. ${ }^{61}$ The oxidation product was attributed to a recalcitrant hydrous oxide type species $^{62}$ however no direct experimental proof of its composition has yet been reported due its low coverage. Illustrated in Fig. 4 is a typical example of an active Pt surface, achieved via

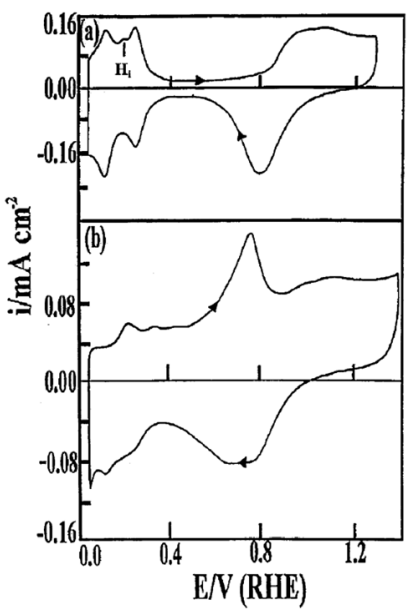

Fig. 4 Cyclic voltammograms recorded in $1 \mathrm{M} \mathrm{H}_{2} \mathrm{SO}_{4}$ at a Pt wire before (a) and after (b) thermal activation via resistive heating in a $\mathrm{N}_{2}$ / $\mathrm{H}_{2}$ atmosphere followed by quenching. The temperature of the wire was $\sim 1310{ }^{\circ} \mathrm{C}$. Reprinted from ref. 63 with permission of Springer.

thermal activation in which a Pt wire was resistively heated in an $\mathrm{H}_{2} / \mathrm{N}_{2}$ atmosphere and subsequently cooled prior to measuring the cyclic voltammogram. ${ }^{63}$ In comparison to a non-activated $\mathrm{Pt}$ surface there are clearly a significant number of new features in the positive sweep which were attributed to the oxidation of active Pt surface sites.

Work from the same group also demonstrated such effects at activated polycrystalline $\mathrm{Au},{ }^{64,65} \mathrm{Pd},{ }^{66,67} \mathrm{Ag}^{68,69}$ and $\mathrm{Cu}^{70,71}$ electrodes via thermal and electrochemical methods. This led to a somewhat controversial model of electrocatalysis named the Incipient Hydrous Oxide Adatom Mediator (IHOAM) model ${ }^{61}$ where it was postulated that electrocatalytic reactions were mediated by a surface confined $\mathbf{M}^{*} /$ hydrous oxide species, however the role that activated chemisorption played in electrocatalytic reactions was not discounted. Other groups reported similar phenomenon with cathodically polarised Pt electrodes ${ }^{72,73}$ and recently such behaviour has been observed on electrodeposited gold, ${ }^{74-77}$ palladium $^{78}$ and copper ${ }^{79}$ nanostructures.

Compton et al. ${ }^{\mathbf{8 0}}$ showed that electrodeposited gold nanoparticles of $40 \mathrm{~nm}$ diameter exhibited a distinct peak (OA1) prior to monolayer oxide formation (OA2). Preceding work by Kolb et $a l .{ }^{81,82}$ showed that the intensity of the OA1 peak increased with the density of surface defects which was confirmed on single crystal surfaces. In Compton's work this was compared to a gold macro electrode where it was shown that the defect level at the latter was much lower than at the nanoparticles as evidenced by the lack of the OA1 peak in the cyclic voltammogram (Fig. 5).

Evidence that these processes are Faradaic in nature was provided by Bond et al. who used large amplitude Fourier transformed ac voltammetry at $\mathrm{Au}^{83}$ and $\mathrm{Cu}^{84}$ electrodes which is an excellent technique for discriminating between capacitive and Faradaic processes in the higher ac harmonic responses. ${ }^{\mathbf{8 5} 86}$ Further work with this technique from this laboratory on electrodeposited gold (Fig. 6) as well as e-beam 

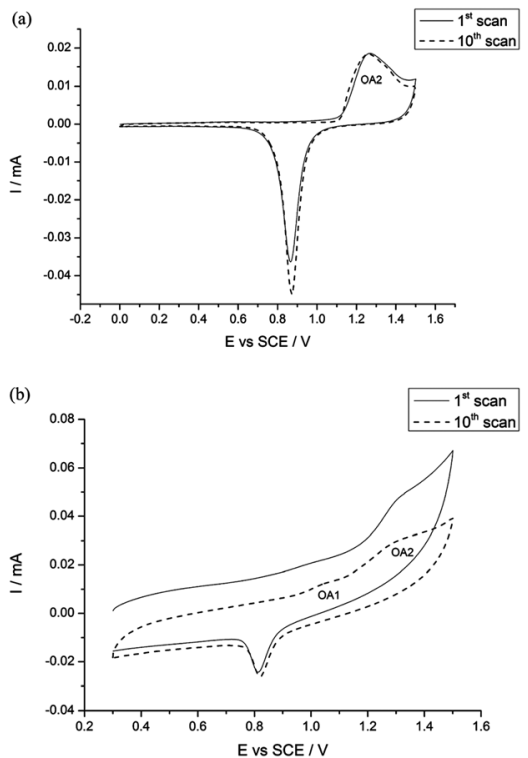

Fig. 5 Cyclic voltammograms recorded in $0.5 \mathrm{M} \mathrm{H}_{2} \mathrm{SO}_{4}$ at (a) macro Au electrode and (b) Au nanoparticles demonstrating the prominence and stability of the OA1 peak at the Au nanoparticles. Reprinted from ref. 80 with permission of the Royal Society of Chemistry.
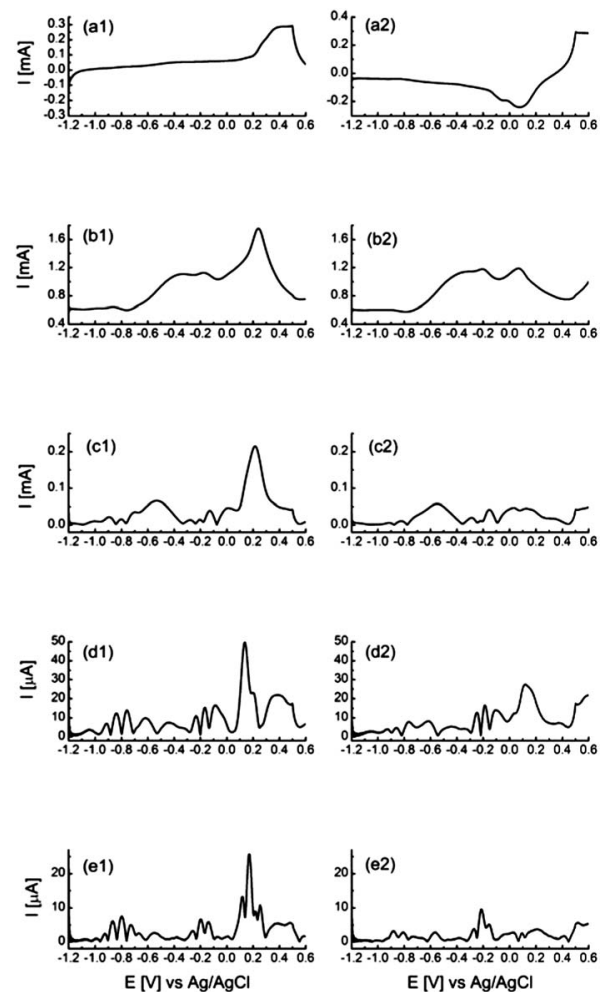

Fig. 6 Large amplitude Fourier transformed ac voltammograms recorded at an electrodeposited porous $\mathrm{Au}$ surface in $1 \mathrm{M} \mathrm{NaOH}$ showing the fundamental to fifth ac harmonic responses. The voltammograms have been split into the forward (a1-e1) and reverse (a2e2) sweeps for clarity. Reprinted from ref. 77 with permission of the Royal Society of Chemistry. evaporated thin gold films further confirmed the presence of this unusual voltammetric behaviour. ${ }^{77,87}$ Several features are observed over the potential range of -1.2 to $0.2 \mathrm{~V}$, with two distinct processes at -0.2 and $-0.8 \mathrm{~V}$ in the higher harmonics, which are not observable in the dc response (Fig. 6a). It was reported that the optimum suppression of background current and high signal to noise ratio was achieved at the 4th ac harmonic response (Fig. 6e). Interestingly the electrocatalytic oxidation of ethanol and the ORR occurred in the regions of active site responses at -0.8 and $-0.2 \mathrm{~V}$ respectively.

Several other techniques have been used to investigate the electrooxidation of metals within the double layer region including using contact electroresistance, ${ }^{88,89}$ electroreflectance techniques, ${ }^{90}$ electrochemical quartz crystal microbalance ${ }^{91}$ and the surface interrogation mode of scanning electrochemical microscopy (SECM).$^{92}$ In the SECM study Bard demonstrated that the coverage of gold with such incipient oxides can be as high as 0.2 of a monolayer.

The presence of this type of behaviour on a wide variety of surfaces is not only important for electrocatalytic reactions but also impacts on the use of metals in other areas. For example gold is often regarded as being biocompatible and inert and used in medical implants. However it was demonstrated that gold can be leached into adjacent tissue via an immune reaction by oxidation, ${ }^{93}$ which may be related to the presence of active sites that are prone to oxidation as shown by the above cyclic voltammetry experiments. The presence of active surface sites also impacts on self-assembled monolayer formation where oxidised surfaces tend to produce less well packed films. ${ }^{94}$

\section{Combining chemical and electrochemical approaches to investigate active site behaviour}

Ideally to obtain the most valuable information regarding the properties of an electrocatalyst surface, experiments should be performed in situ. Therefore a variety of interesting approaches have been adopted to investigate active site behaviour rather than using ex situ methods such as high resolution transmission electron microscopy (HRTEM). However this raises a difficulty in that active sites are notoriously difficult to visualise given that they are regarded as being anywhere from point defects, to kinks, clusters or extended defects such as steps. Scholz et al. ${ }^{95,96}$ reported an elegant method of investigating active sites whereby he removed them via chemical means to probe their impact on electrocatalytic processes. This selective "knock-out" of active sites was achieved by removing surface asperities on gold through a chemical polishing procedure using Fenton's reagent where $\mathrm{OH}$ radicals attack and dissolve the metal protrusions and oxidise the smooth parts of the surface. This results in a decrease in the surface area of the gold as well as severe inhibition of electrocatalytic activity for the ORR (Fig. 7).

Therefore it was postulated that the sites at the protruding asperities were the location of the active sites for the ORR. The data was consistent with the selective disappearance of reactive 


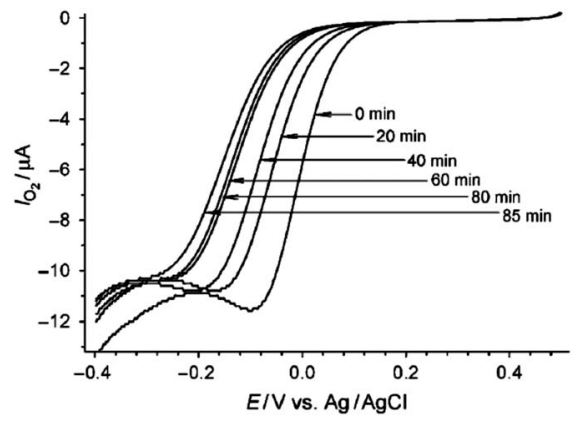

Fig. 7 Cyclic voltammograms illustrating the reduction in activity for the ORR in $0.1 \mathrm{M} \mathrm{H}_{2} \mathrm{SO}_{4}$ at a $\mathrm{Au}$ electrode treated with Fenton's reagent for various times. Reprinted from ref. 96 with permission of Wiley.

$\mathrm{Au}$ atoms with partially filled $\mathrm{d}$ orbitals that can stabilise free radical intermediates, leaving behind only the unreactive $\mathrm{Au}$ atoms with fully filled $d$ orbitals. This was confirmed by probing the inner sphere hydroquinone reduction reaction which was also inhibited whereas the outer sphere reaction for the $\mathrm{Ru}^{\mathrm{III}} /$ $\mathrm{Ru}^{\mathrm{II}}$ couple remained unperturbed. Dutta $e t$ al. used the same protocol for investigating the electrocatalytic activity of electrodeposited $\mathrm{Au}$ nanoparticles where a similar decrease in activity was found after treatment with Fenton's reagent. ${ }^{97}$ Scholz et al. extended this work by similar studies on Pt, Pd and $\mathrm{Ag}$ electrodes. ${ }^{98}$ Interestingly distinctly different behaviour was observed on $\mathrm{Ag}$ and $\mathrm{Au}$ compared to Pt and Pd whereby severe inhibition of the hydroquinone reduction reaction was observed on the former but not the latter group of metals. This indicated that the active sites on $\mathrm{Ag}$ and Au were associated with the surface asperities whereas in the case of Pt and Pd they were present on the regular structure and not concentrated at the asperities.

Instead of selectivity removing active sites from metal surfaces work from this laboratory demonstrated that active sites could be used to promote the formation of foreign metal atoms on the surfaces of metals via an electroless deposition method. With this approach the facile oxidation of active sites on electrodeposited gold, which occurs at potentials well below that for bulk gold oxidation as described above, was used to drive the spontaneous deposition of silver and palladium on to the surface. ${ }^{77}$ Fig. 8 clearly shows the deposition of Ag and Pd nanoparticles onto the surface of the dendritic gold samples. Given that the standard reduction potentials for $\mathrm{Ag}^{+} / \mathrm{Ag}(0.799$ vs. SHE) and $\mathrm{Pd}^{2+} / \mathrm{Pd}(0.915)$ are significantly lower than that for $\mathrm{Au}^{3+} / \mathrm{Au}(1.50 \mathrm{~V} v s$. SHE) suggests that it is the oxidation of active sites which is the driving force for the reduction of the metal salts as the reaction is thermodynamically unfavourable at bulk gold. This effect was not only confined to nanostructured materials but also occurred at e-beam evaporated thin films of $\mathrm{Au}^{87}$ and $\mathrm{Pd} .{ }^{78}$ Interestingly, visualisation of nanoparticles with SEM was not achieved at these relatively smooth films. However EDX mapping of a gold TEM grid that was nominally (100) in character using HRTEM revealed a sparse but relatively even coverage of silver across the surface. ${ }^{87}$ This indicates that even for nanostructured gold, active sites are likely to be present
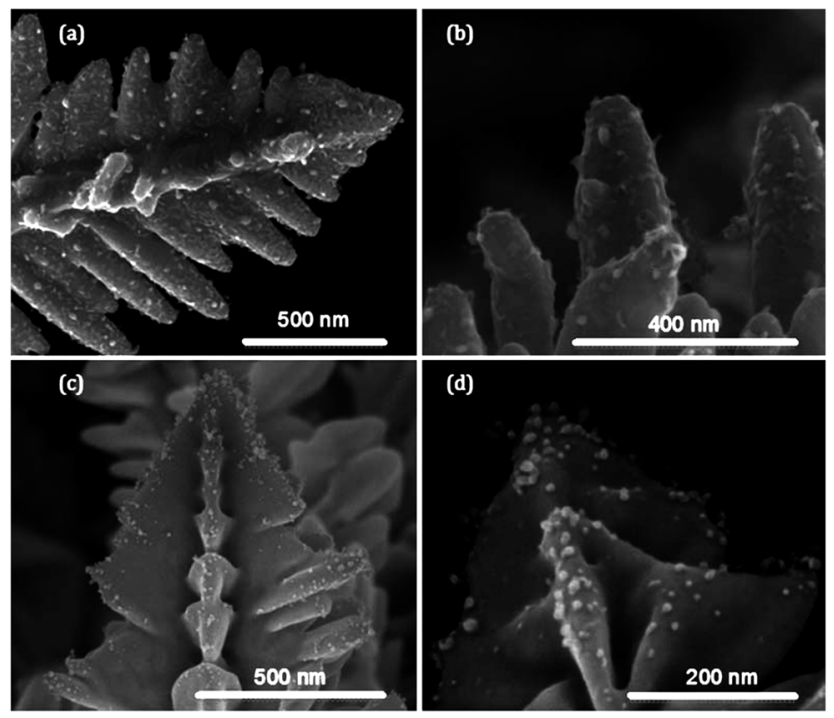

Fig. 8 SEM images of electrodeposited porous Au decorated with (a and b) Ag and ( $\mathrm{c}$ and d) Pd via a spontaneous electroless deposition approach. Adapted from Fig. 11 in ref. 77 with permission of the Royal Society of Chemistry.

across the entire sample but apparently more concentrated in certain regions as shown in Fig. 8. As was the case with Scholz's work outer sphere reactions remained unperturbed at the modified surfaces but inner sphere reactions like the HER and ORR were significantly affected by the presence of the second metal as expected, which either increased or decreased electrocatalytic activity depending on the final bimetallic combination and reaction of interest. For instance ethanol oxidation was significantly improved at $\mathrm{Pt} / \mathrm{Au}$ surfaces ${ }^{99}$ compared to only $\mathrm{Pt}$ whereas the HER was inhibited at Ag/Au surfaces compared to $\mathrm{Au}^{87}{ }^{87}$ What is interesting to note with this approach is that the surface area of the electrode does not change significantly but results in significant changes in activity such as an $80 \%$ decrease in current magnitude for the HER on $\mathrm{Ag} / \mathrm{Au}$ even though only $7 \%$ of the surface is decorated with Ag. This supports the hypothesis that the surface concentration of defect sites on metal surfaces is quite low.

This approach was also used by Chung and co-workers ${ }^{100}$ with electrochemically treated gold electrodes to induce active sites which were decorated with Pt and Pd and shown to be highly effective electrocatalysts for the oxidation of methanol and ethanol under alkaline conditions. Intriguingly Pt or Pd nanoparticles were also not observed on the surface via HRTEM but confirmed via ICP-AES which gave an estimated coverage of active sites of $5 \%$. Recently Wu demonstrated that Au nanoparticles of less than $3 \mathrm{~nm}$ in diameter (which are expected to be defect rich) also promoted the electroless deposition of both $\mathrm{Ag}$ and $\mathrm{Cu}$ on their surface. ${ }^{101}$ It should be noted that such processes have also been observed for the spontaneous decoration of noble metals such as Pt with Ru or vice versa ${ }^{102,103} \mathrm{It}$ was assumed for the case of Pt decoration with Ru that a local cell mechanism was proposed where $\mathrm{Pt}$ is oxidised to $\mathrm{Pt}-\mathrm{OH}$ that facilitates metal deposition ${ }^{103}$ which would be consistent with the oxidation of active sites. 
El-Deab has used a technique of reductive desorption of SAMs to investigate the electrocatalytic behaviour of electrodeposited gold nanoparticles. In this method gold is chemically modified by cysteine which is then electrochemically removed from the surface. With this method stripping peaks are observed at distinct potentials corresponding to the (111), (100) and (110) crystal planes which allows the surface concentration of each plane to be determined. Although this work does not explicitly investigate active site behaviour it demonstrated that the $\mathrm{Au}(100)$ and $\mathrm{Au}(110)$ faces were more active than $\mathrm{Au}(111)$ for the ORR under alkaline conditions. ${ }^{104}$ Because the reduction of cysteine from $\mathrm{Au}$ (111) occurs at a more positive potential it could be selectivity removed to reveal bare $\mathrm{Au}$ (111) facets while a sub monolayer of cysteine covered any exposed $\mathrm{Au}$ (100) and $\mathrm{Au}$ (110) facets. With this approach a polycrystalline gold electrode was converted into a pseudo Au (111) single crystal electrode which exhibited the same behaviour for the ORR as that seen for a true single crystal surface in the same medium. ${ }^{\mathbf{1 0 5}}$ Such an approach offers a route to engineering the crystallography of gold nanomaterials.

\section{Visualising nanomaterials}

There have been numerous spectroscopic techniques employed to characterise the performance of electrocatalysts under working conditions such as infrared reflection absorption spectroscopy, differential reflectance spectroscopy and secondharmonic generation which give excellent information on interfacial phenomena and the adsorption of species on electrode surfaces. These approaches have recently been reviewed in detail for Pt (111) surfaces by Scherson et al. ${ }^{\mathbf{1 0 6}}$ Watanabe has reported the electrochemical cell plus X-ray photoelectron spectroscopy (EC-XPS) technique using the emersion approach to elucidate the mechanism of the ORR at well-defined metal surfaces by observation of adsorbed oxygen, hydroxyls and water. ${ }^{107}$ All of these types of measurements if used in combination with in situ STM experiments can provide detailed information on morphological effects such as surface reconstruction and the role of adsorbed species on electrode surfaces. Another powerful in situ spectroscopic technique is X-ray absorption fine structure (XAFS) analysis which has been used to monitor the local coordination structures and oxidation states of catalysts in working polymer electrolyte fuel cells (PEFC) ${ }^{108}$ This technique is particularly useful in determining the degradation mechanism of fuel cells. A recent development in this area was reported by Tada and co-workers ${ }^{\mathbf{1 0 9}}$ who demonstrated four-dimensional visualisation of structures/ chemical states of a Pt/C cathode catalyst layer in membrane electrode assemblies (MEAs) of a PEFC by a laminography-XAFS method that combined three dimensional X-ray computed laminograph imaging and XAFS spectroscopy (Fig. 9).

Fig. 9 shows three-dimensional images of the Pt quantity in fresh and degraded MEAs. This enabled the visualization of aggregation behaviour induced under voltage-cycling processes. The spatially-resolved three-dimensional laminography-XANES revealed the heterogeneous presence of aggregation and chemical states of the Pt nanoparticle catalysts in the MEA.
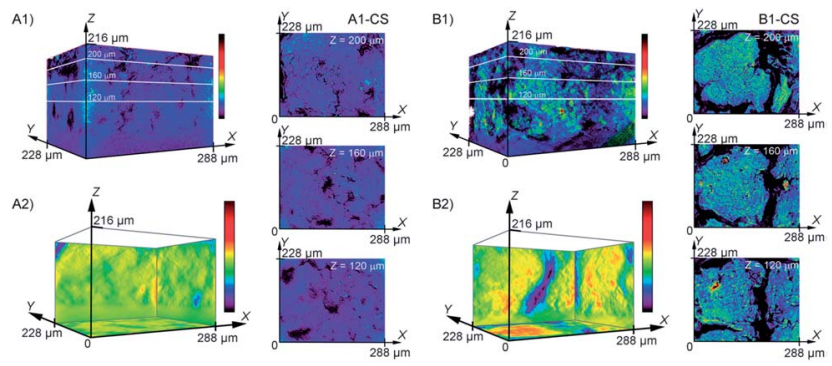

Fig. 9 The distribution of Pt catalysts in the cathode catalyst layers of (A) fresh and (B) degraded MEA as observed by 3D-laminographyXANES. The change in colour intensity reflects the quantity of Pt. Cross sectional images of the MEA are also shown in the $X-Y$ plane. (A2) and (B2) are 2D projections of the summation of the change of intensity onto the $X-Y, Y-Z$, and $Z-X$ planes of (A1) and (B1). Reprinted from ref. 109 with permission of Wiley.

Although not specifically related to the identification of active sites the ability to monitor the distribution and agglomeration of particles within a working fuel cell is critical to understanding degradation mechanisms.

A particular drawback of investigating nanoparticle electrocatalysts is that they are often employed via drop casting onto an electrode surface or support using a Nafion slurry. This results in a surface which contains a catalytic ensemble and makes interpretation related to size and shape difficult to ascertain due to overlapping diffusion fields of the individual particles. Therefore there has been recent interest in observing electrocatalytic reactions in situ at the single nanoparticle level. A significant development by Unwin and co-workers has been the scanning electrochemical cell microscopy (SECCM) technique. ${ }^{110}$ Details of the principles of operation can be found in ref. 110. In essence a dual barreled theta pipet pulled to ca. $1 \mu \mathrm{m}$ diameter serves as a mobile localised electrochemical cell. During the experiment the tip is scanned across the surface and catalytic activity, topography and conductivity are measured. This has allowed for unprecedented spatial and electrochemical resolution of electrode processes which has resulted in the observation of electrocatalytic processes at individual nanoparticles or if desired an ensemble of nanoparticles. This opens up the possibility of studying the role of shape, size and support in a single measurement. Indeed nanoparticles on any type of support can in principle be investigated. This is in contrast to previous SECM experiments that investigated the effect of $\mathrm{Pt}$ nanoparticle shape on the ORR. In that particular study a suspension of nanoparticles was dispensed on to a solid support which resulted in an ensemble of nanoparticles contained within a $100 \mu \mathrm{m}$ diameter dot. By scanning a nanoparticle array containing isolated dots of nanoparticles of different shapes under tip generation substrate collection mode the ORR was found to be most active for hexagonal shaped nanoparticles. ${ }^{111}$ This approach is useful as a rapid electrocatalyst screening technique to identify shape effects but also has been used to identify optimal composition ratios for bimetallic electrocatalysts. ${ }^{112}$ However using the SECCM technique Unwin and co-workers were able to investigate the electrocatalytic activity of individual electrodeposited Pt NPs on 
single walled carbon nanotubes. ${ }^{\mathbf{1 1 3}}$ By controlling the potential they were able to investigate the ORR, HER and Pt oxide formation reactions as shown in Fig. 10 while simultaneously recording topography and conductivity maps. It is immediately apparent that the reactivity is not homogeneous across the individual particles. By analysing the reactivity maps and correlating with FE-SEM measurements they reported that particles of similar size but different morphology exhibited different reactivity.

A further development in this area was using the SECCM approach in combination with nanoparticle collision experiments. The latter type of experiments have been investigated by Bard $^{114-116}$ and Compton ${ }^{117118}$ whereby an ultramicroelectrode (UME) is placed in a dilute solution of nanoparticles which results in collisions at the electrode surface. Upon a collision event an electrocatalytic reaction takes place (such as HER, hydrazine oxidation) that otherwise would not occur at the potential applied to the UME and a current spike is detected. This technique can provide information of nanoparticle size and size distribution using a purely electrochemical approach and in principle heterogeneous electron transfer kinetics at the single nanoparticle level can be measured. ${ }^{114}$ Using the SECCM approach the collision event was limited to a significantly smaller area of the collector electrode and excellent signal-tonoise ratios were achieved. ${ }^{119} \mathrm{Au}$ NPs were investigated on HOPG surfaces and a higher onset potential for the ORR compared to bulk gold was reported. A particularly interesting aspect of the study was the ability to land an individual nanoparticle on to a TEM grid under conditions where the collision frequency was of the order of tens of seconds. A single Au nanoparticle was landed on to a TEM grid and probed via cyclic voltammetry for the oxidation of hydrazine. After electrochemical characterisation, the same nanoparticle could be imaged with TEM as shown in Fig. 11. This approach will be invaluable in determining the influence of nanoparticle shape on electrocatalytic processes. An interesting aspect would be to characterise the individual nanoparticle in supporting electrolyte only to determine if any active site type responses are

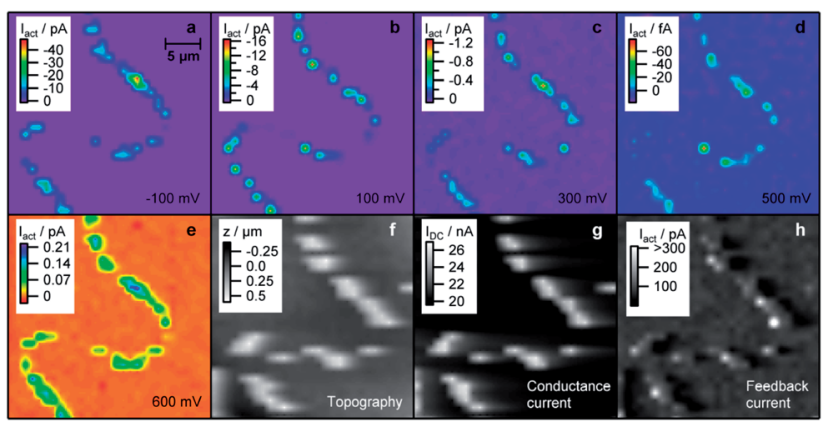

Fig. 10 SECCM images of Pt nanoparticles on an individual carbon nanotube biased at different potentials illustrating reactivity maps and the corresponding topography of the sample. Also shown is the conductance recorded between the two barrels of the SECCM probe and the ac component of the conductance current (feedback current). Reprinted with permission from ref. 113. Copyright (2011) American Chemical Society.
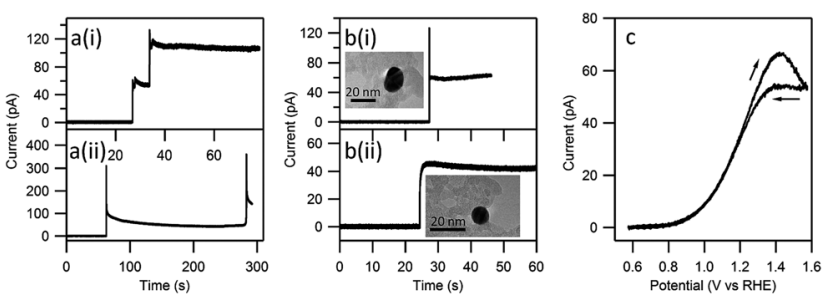

Fig. 11 Illustration of the landing of multiple and single Au NPs on a carbon coated TEM grid. After detection of a single landing event (b) the same nanoparticle could be imaged in the TEM and it's electrocatalytic behaviour for the oxidation of hydrazine could be investigated (c). Reprinted with permission from ref. 120. Copyright (2012) American Chemical Society.

present as observed at stepped single crystal surfaces and activated polycrystalline surfaces.

A further example of the power of the SECCM technique was shown by investigating the electrocatalytic activity of a polycrystalline Pt surface for the surface sensitive $\mathrm{Fe}^{2+/ 3+}$ system. By correlating SECCM activity maps with electron backscatter diffraction images the reaction was found to be controlled by the surface orientation of the grains in perchlorate medium whereas in sulphate medium a significant increase in electron transfer rate occurred at the grain boundaries. ${ }^{119}$

Ex situ TEM has been used extensively to characterise nanomaterials of different size and shape where the quality of imaging allows one to visualise the exposed facets which influence electrocatalytic activity. A particularly interesting development was a recent study using aberration-corrected scanning transmission electron microscopy (STEM) in the highangle annular dark-field (HAAD) imaging mode which revealed the presence of low coordination $\mathrm{Au}$ adatoms on truncated octahedral gold clusters $\left(\mathrm{Au}_{923 \pm 23}\right)$ (Fig. 12). ${ }^{121}$ It was concluded that $70 \%$ of the species on the surface were in fact gold adatoms with similar probabilities of being found on the (100) and (111) facets which migrate between facets upon repetitive imaging (compare images (c) and (d) in Fig. 12). This migration of adatoms was found to be dependent on beam intensity but extrapolation to zero dose showed that adatoms were mobile in the purely thermal regime. Although performed ex situ under vacuum conditions such an approach still offers fascinating insights into the structure of these nanomaterials which would not only affect electrocatalytic reactions but gas phase catalysis, and nanomaterial growth.

In an effort to combine electrochemical studies with the power of TEM imaging Arenz and Mayrhofer developed an in situ and non-destructive identical location TEM technique (IL-TEM) to observe the identical locations of a catalyst before and after electrochemical treatment. ${ }^{122}$ They investigated an important consideration for the application of any electrocatalyst and that is stability. Even though this can be monitored quite readily by electrochemical methods under accelerated ageing conditions such as repetitive cycling or chronoamperometry, identifying the source of any instability is challenging as it can originate from catalyst dissolution, particle agglomeration, Ostwald ripening which reduces surface 

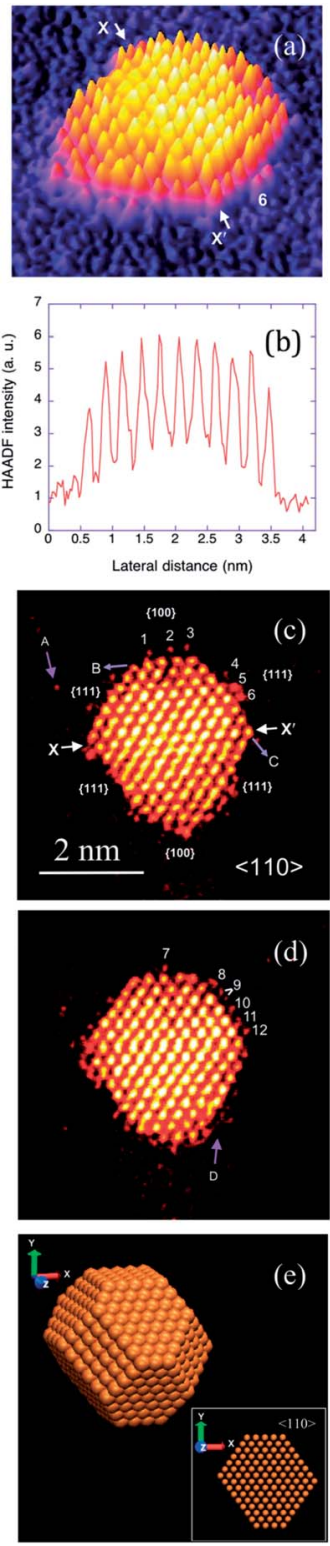

Fig. 12 (a) 3D intensity plot of the HAADF-STEM image of one $\mathrm{Au}_{923}$ cluster, (b) intensity profile along the $X-X^{\prime}$ line, (c) profile view of (a) and (d) is after a further 6 frames have been taken, (e) an atomic model of a truncated-octahedral $\mathrm{Au}_{923}$ cluster. Reprinted with permission from ref. 121. Copyright (2011) American Chemical Society.

area, or corrosion of the support. Using IL-TEM a commercial catalyst was investigated to understand its degradation with time. By having the ability to image the exact spot before and after electrochemical testing the mechanism of degradation can be determined under different conditions. Illustrated in Fig. 13 is a IL-TEM study of a commercial Pt/C catalyst showing both particle movement and agglomeration.

By varying the experimental conditions such as no of cycles, the potential window, presence of $\mathrm{CO}$, particle detachment and displacement of the support was observed. The same group followed up this work using this technique by investigating different carbon supports ${ }^{\mathbf{1 2 3}}$ and the confinement of nanoparticles within a nanoporous support. ${ }^{124}$
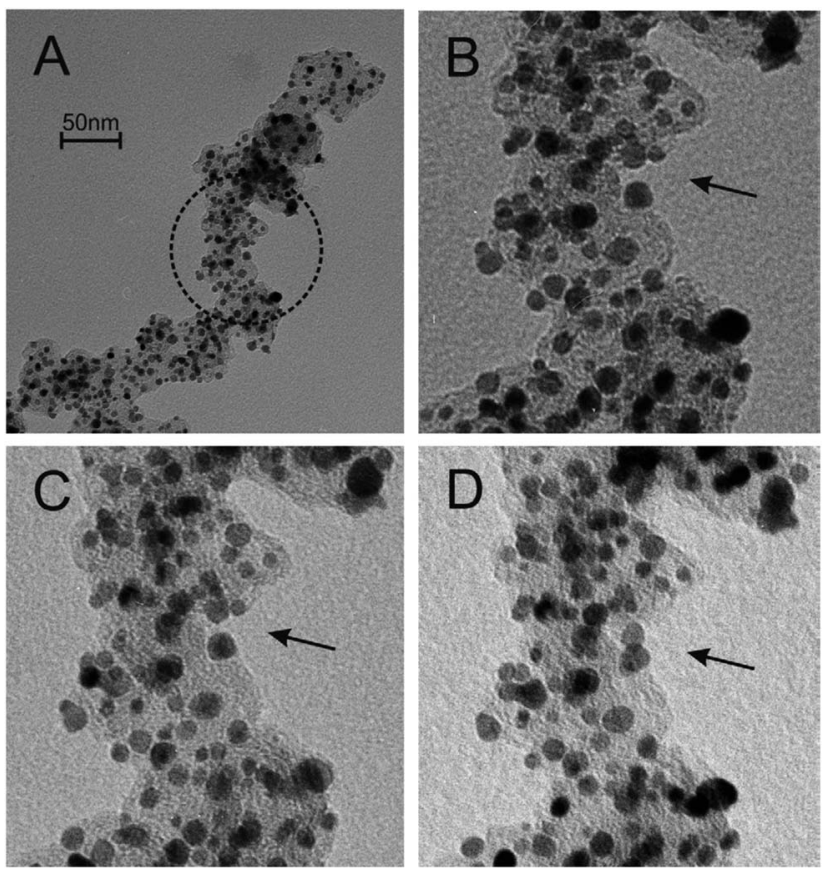

Fig. 13 IL-TEM images of a commercial Pt/C catalyst before $(A+B)$ and after $(C+D)$ electrochemical cycling showing the movement and agglomeration of Pt catalyst particles. Reprinted from ref. 122 with permission of Elsevier.

\section{Designing an active site}

It has been discussed that active sites are present on a variety of surfaces and play an important role in electrocatalytic activity. However, another critical aspect of the field is the investigation of bimetallic materials which exhibit synergistic effects to promote a wide variety of electrocatalytic reactions. This has numerous benefits in not only increasing efficiency but decreases cost by minimising expensive precious metals and can also inhibit electrodissolution. There have been numerous studies on fabricating and testing bimetallic combinations as either alloys or core-shell materials to observe such promotional effects for many important electrocatalytic reactions and specific combinations such as $\mathrm{Pt} / \mathrm{M}$ and $\mathrm{Pd} / \mathrm{M}(\mathrm{M}=\mathrm{Cu}, \mathrm{Ag}, \mathrm{Au}, \mathrm{Ru}, \mathrm{Fe}$ and $\mathrm{Pb}$ ) have been widely reported. ${ }^{25,31-33,36-39,41,43,44,78,87,103,112,125,126}$ Many of these studies used density functional theory (DFT) calculations to explain activity based on the adsorption of reactants and intermediates created during the course of the reaction. However what is interesting to note is the rational design of an active site via theoretical predictions. Greeley and Nørskov predicted with density functional theory (DFT) calculations the influence of bimetallic composition on the HER for a large matrix of metals that included different ratios of the solute and solvent metal where the critical parameter was the metalhydrogen bond strength. ${ }^{127,128}$

Given the recent success of the $\mathrm{Pt}_{3} \mathrm{Ni}$ (111) extended surface as a highly effective ORR electrocatalyst the same group investigated a host of $\mathrm{Pt}_{3} \mathrm{X}$ and $\mathrm{Pd}_{3} \mathrm{X}$ materials that could form a skin with either Pt or $\mathrm{Pd} .{ }^{129}$ In the original report for $\mathrm{Pt}_{3} \mathrm{Ni}$ (111) it was found that the material had an optimum d-band centre position and 
arrangement of atoms of the surface which was Pt rich. ${ }^{\mathbf{1 3 0}}$ From DFT calculations it was predicted that $\mathrm{Pt}_{3} \mathrm{Sc}$ and $\mathrm{Pt}_{3} \mathrm{Y}$ polycrystalline materials would be significantly better electrocatalysts than pure Pt and this was experimentally verified. In fact the material was closer in activity to $\mathrm{Pt}_{3} \mathrm{Ni}(111)$ than polycrystalline $\mathrm{Pt}_{3} \mathrm{Ni}$ which is less active. ${ }^{129}$ Recently Nørskov used DFT calculations to describe trends in activity for the electroreduction of $\mathrm{CO}_{2}$ to $\mathrm{CO}$ where $\mathrm{Cu}, \mathrm{Ag}$ and $\mathrm{Au}$ were found to be the best but not as effective as enzymes such as CODH. ${ }^{131}$ Chorkendorff et al. designed a catalyst for the CO electrooxidation reaction based on $\mathrm{Cu} / \mathrm{Pt}$ (111) where their predictions allowed them to tailor the configuration of $\mathrm{Cu}$ atoms in $\mathrm{Pt}(111)$ to control binding of $* \mathrm{H}$, ${ }^{*} \mathrm{OH}$, and ${ }^{*} \mathrm{CO}$ species to give the best performance. ${ }^{\mathbf{1 3 2}}$ Liu et al. used DFT in combination with the periodic continuum solvation model based on modified-Poisson-Boltzmann electrostatics to predict that Pt octahedrons of $\sim 2 \mathrm{~nm}$ should be the optimum size and geometry for Pt single nanoparticles for the ORR. Furthermore they predicted that using an inert metal such as Au as the frame for the Pt nanoparticles, that exposed Pt (111) sites are the active site for oxygen reduction and with such an architecture would not only prevent the initial oxygen induced corrosion at the edge sites but also significantly improve activity. ${ }^{\mathbf{1 3 3}}$

DFT is an extremely useful tool when combined with experimentation, however a recent review of the topic ${ }^{\mathbf{1 3 4}}$ pointed out that there is a lack of detailed understanding of how to approximate functionals and at present there are more calculations, both good and bad, being carried than ever before. However Burke suggested that new and more general standard approximations will be developed to keep the field moving forward. ${ }^{134}$ Given the complex and non-perfect nature of nanomaterials, which undoubtedly change within the dynamic environment of an electrocatalytic reaction, will make the area of theoretical prediction of activity a significant challenge.

The discovery of the unprecedented activity of the $\mathrm{Pt}_{3} \mathrm{Ni}(111)$ extended surface for the ORR suggested that mimicking this system at high surface area chemically synthesised nanomaterials was the way forward, however to date this has not come to fruition for practical catalysts. ${ }^{135}$ As seen in the field of electrocatalysis there are significant differences in activity observed at the nanoscale and at bulk single crystal metals. A recent study by Zou et al. ${ }^{136}$ on $\mathrm{Pt}_{3} \mathrm{Ni}$ nano-octahedra terminated with (111) facets demonstrated this where their material had a specific activity that was 4 times less than the extended single crystal surface reported by Marković. ${ }^{130}$ Therefore Stamenkovic and co-workers designed a new class of electrocatalysts based on mesostructured multimetallic thin films with adjustable structure and composition. ${ }^{\mathbf{1 3 5}}$ This approach created catalysts that could emulate the $\mathrm{Pt}$ skin- $\mathrm{Pt}_{3} \mathrm{Ni}$ (111) system and bridge the world of extended surfaces, with superior activity, and nanoscale systems with high specific surface area, to harvest maximal utilisation of precious metals. In principle this creates a material that operates in between different physical regimes that exhibit distinct functional behaviour. Pt alloys of different composition and thickness were deposited by magnetron sputtering onto an array of solid molecular whiskers (to provide high surface area) based on perylene red which is an organic pigment (Fig. 14).

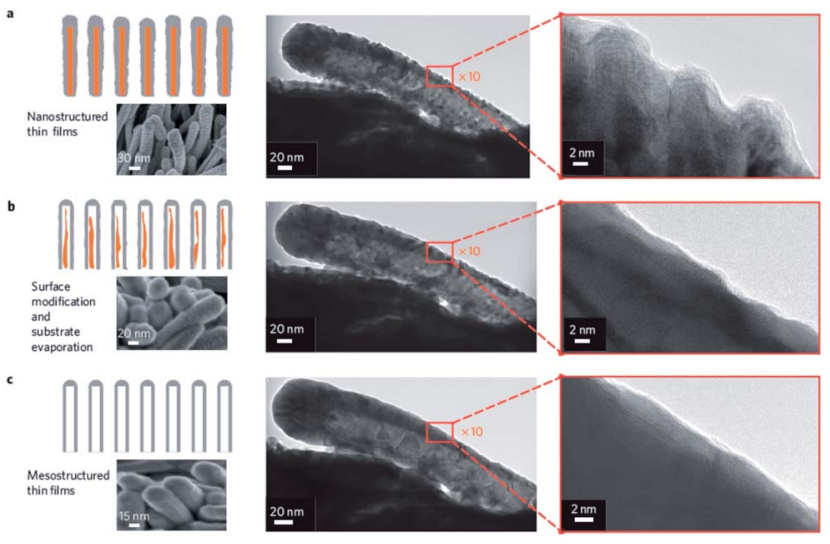

Fig. 14 In situ transformation from a nanostructured into mesostructured PtNi thin film during annealing from RT to $400{ }^{\circ} \mathrm{C}$. HRTEM images shows this process occurring at a single nanowhisker. Reprinted from ref. 135 with permission of Nature Publishing Group.

After annealing in a reductive atmosphere of $\mathrm{Ar}$ and $\mathrm{H}_{2}$ the surface changes from a random orientation into a homogeneous structure with visible crystal domains which also removes the organic template and results in a mesoporous structure (Fig. 14c). Further HRTEM imaging revealed the presence of (111) facets at the surface and a decrease in the number of uncoordinated sites. The decrease in surface concentration of the latter was suggested to improve the stability of the material by removing the most highly active sites. The PtNi mesoporous thin film produced in this manner showed a 20 fold enhancement in specific activity over a commercial Pt catalyst for the ORR.

\section{Single atom electrocatalysts}

Although isolated adatoms or un-coordinated metal atoms are highly reactive they are often unstable when present on the parent metal surface due to over oxidation, mobility and sintering. However harnessing this type of activity would be highly desirable if instability issues could be alleviated. To take advantage of the properties of single atoms a new approach in the field is to embed single atoms or sub-nanoclusters in a host matrix which offers the required stability. This has been achieved in the area of gas phase heterogeneous catalysis for both oxidation and reduction reactions using noble metals such as $\mathrm{Au}$ and Pt isolated on ceria, titania, iron oxide, alumina and silica where the active site has been reported to be cationic $\mathrm{Pt}-\mathrm{O}$ and $\mathrm{Au}-\mathrm{O}$ species. ${ }^{137}$ However, there have been relatively fewer reports on transferring this concept to electrocatalytic processes. Recently Sun et al. ${ }^{\mathbf{1 3 8}}$ deposited single atoms of Pt on graphene nanosheets through an atomic layer deposition process. Using this approach they could vary the Pt content from isolated single atoms, to sub-nanometer sized clusters up to Pt nanoparticles (Fig. 15). They showed that single-atom catalysts exhibited significantly improved catalytic activity (up to 10 times) over that of the state-of-the-art commercial Pt/C catalyst. They postulated on the basis of X-ray absorption fine structure studies that the low-coordination and partially 

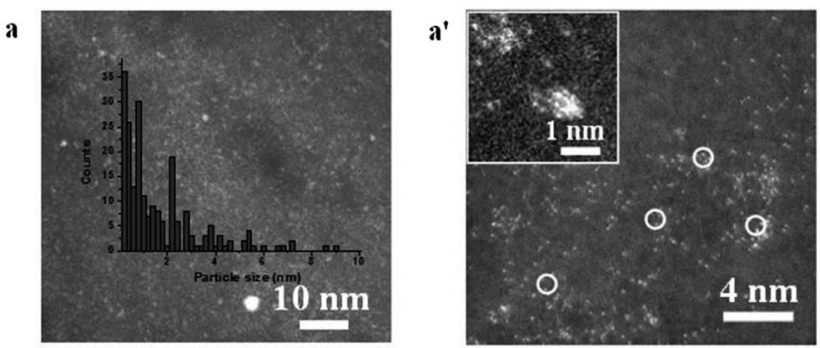

b

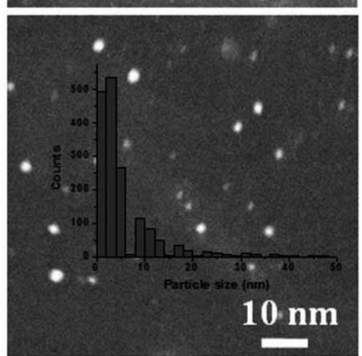

c

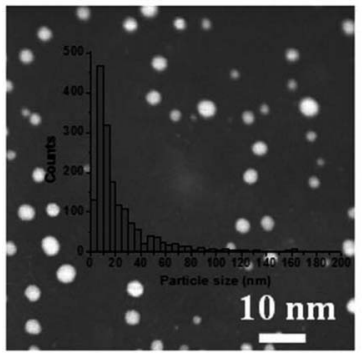

$b^{\prime}$

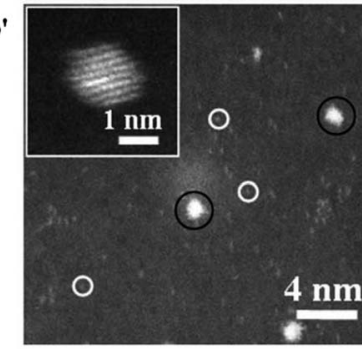

$c^{\prime}$

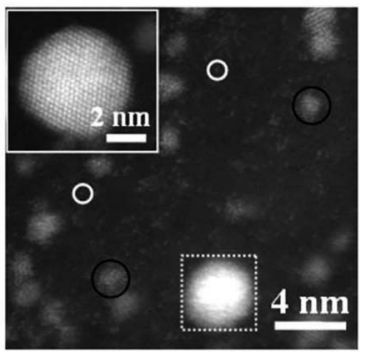

Fig. 15 HAADF-STEM images of Pt/GNS samples with increasing number of atomic layer deposition cycles. Reprinted from ref. 138 with permission of Nature Publishing Group.

unoccupied densities of states of the $5 \mathrm{~d}$ orbital of Pt atoms were responsible for the excellent activity.

Schiffrin et al. ${ }^{139}$ reported that isolated alloying atoms of $\mathrm{Pd}$ on a $\mathrm{Au}$ host matrix enhanced the selectivity for oxygen reduction to $\mathrm{H}_{2} \mathrm{O}_{2}$ compared to pure $\mathrm{Au}$. 95\% selectivity was achieved at a Pd molar percentage of $8 \%$. Further increasing the Pd content was highly detrimental to selectivity which reduced to $10 \%$ when $50 \% \mathrm{Pd}$ was used. The enhanced $\mathrm{H}_{2} \mathrm{O}_{2}$ production was attributed to the presence of Pd monomers surrounded by gold at the surface of $\mathrm{Au} / \mathrm{Pd}$ nanoalloys whereas the decrease at Pd concentrations above $15 \%$ was due to the presence of contiguous Pd atoms, in agreement with their DFT modeling results suggesting that two adjacent $\mathrm{Pd}$ atoms should support $\mathrm{H}_{2} \mathrm{O}$ formation instead of $\mathrm{H}_{2} \mathrm{O}_{2}$. DFT calculations also revealed that Pt and Ru would also be suitable guest metals in the Au host.

The idea of imbedding a foreign metal atom in a host matrix has also been used extensively for carbon based electrocatalysts. Indeed some of the early reports on the electrocatalytic activity of carbon nanotubes could in fact be attributed to the presence of metallic impurities incorporated into the CNTs during the synthesis procedure. ${ }^{\mathbf{1 4 0}}$ At present studies on graphene face a similar issue as shown by Pumera et al. who demonstrated that the common practice of transferring CVD grown graphene to another substrate may involve contamination by metals such as Fe and Ni. ${ }^{141}$ The same group has shown in many reports that producing graphene oxide and graphene can be problematic with regards to the presence of metallic impurities. ${ }^{\mathbf{1 4 2 , 1 4 3}}$ Again any electrocatalysis study undertaken with such a material would be dictated by the active metal atoms.

It has been well established that doping carbon whether it be graphite, CNTs or graphene with nitrogen improves its ability to catalyse electrochemical reactions. ${ }^{\mathbf{1 4 4 , 1 4 5}}$ However the best performance is generally achieved under alkaline conditions for the ORR while performance is poor under acidic conditions. Recent breakthroughs have shown that nitrogen doped carbon containing Co and Fe species improves electrocatalytic performance which is reviewed in ref. 146. A very recent example by Müllen et al. ${ }^{\mathbf{1 4 7}}$ showed that cobalt-nitrogen-doped carbon (1.3 atomic\% $\mathrm{Co}$ ) and iron-nitrogen doped carbon (1.5 atomic\% $\mathrm{Fe}$ ) in a mesoporous form to increase surface area exhibited excellent performance for the ORR under acidic conditions with the transfer of $>3.95$ electrons where the high surface area exposed a large number of active sites for the reaction to proceed. The metal species were uniformly dispersed in the entire carbonnitrogen matrix at the atomic or subnanoscale level where the metal-nitrogen sites were identified as being the active site for the ORR. Chisholm et al. have shown that single atoms of $\mathrm{Nb}$ trapped within graphitic layers produce a redistribution of d-band electrons and become surprisingly active for $\mathrm{O}_{2}$ adsorption and dissociation, and significantly resist chemical and thermal coarsening resulting in a highly stable electrocatalyst for oxygen reduction. ${ }^{\mathbf{1 4 8}}$ Koper et al. have predicted with DFT calculations that graphitic materials and gas-phase porphyrins with active square-planar sites with 4 nitrogen atoms and transition metals belonging to groups 7 to 9 in the periodic table may have high catalytic activity towards the ORR and the oxygen evolution reaction. ${ }^{\mathbf{1 4 9}}$

\section{Conclusions and outlook}

In this article I have reviewed several types of experimental investigations into elucidating the nature of active sites on metal surfaces. In general the active site which dominates many electrocatalytic processes, even though their coverage is seemingly very low, is generally regarded as consisting of adatoms or clusters of adatoms on the surface with low coordination number. This property gives them highly characteristic electrochemical behaviour as observed by unique voltammetric signatures in the double layer and oxide formation/reduction regions recorded at single crystal electrodes with steps and kinks, polycrystalline surfaces and chemically synthesised nanoparticles. Intriguingly, these active sites can be knocked out or utilised for the spontaneous deposition of a foreign metal species to investigate their role in electrocatalytic processes. However, a critical factor in understanding how a material performs as an electrocatalyst is the ability to relate structure to activity. This can be achieved remarkably well at single crystal surfaces with the aid of in situ STM imaging but is significantly more challenging when dealing with commercially applicable nanomaterials. Indeed relating the fundamental insights gained at single crystal surfaces can be difficult to translate to chemically synthesised nanomaterials. An exciting development is the combination of both length scales where 
mesoporous thin films have been utilised to emulate the activity of Pt (111)-skin materials but in a high surface area form. Ex situ methods such as HRTEM and HAAF-STEM offer a wealth of information on the structure of nanomaterials, even at the single atom level, but whether this structure is preserved during the course of an electrocatalytic experiment needs to be investigated in detail. IL-TEM offers such an approach to answer such a question where particle movement and agglomeration is observable post reaction, but visualising active sites at the adatom level is elusive. In situ spectroscopic techniques also provide a wealth of information on the chemistry at the surface of an electrocatalyst in terms of adsorption of reactants and intermediates, changes in oxidation state and even distribution within a MEA using 4D-XANES experiments. However these approaches still cannot provide a clear indication of structureactivity relationships as the structure may change during the course of the experiment. A significant step to addressing this is the development of in situ electrochemical imaging of electrocatalysts under potential control. It can now be achieved at the single nanoparticle level at sizes of around $10 \mathrm{~nm}$. This approach will be extremely useful for investigating nanoparticle-support interaction effects, nanoparticle size and shape without the influence of the ensemble effect which hinders insights gained at drop cast samples. Achieving higher resolution with this technique and investigating clusters of adatoms would be truly exciting. However, no one technique will provide the answer and therefore a combination of in situ and ex situ techniques that probe the morphology as well as the chemistry that happens at the surface of both well-defined surfaces and nanomaterials suitable to applications is necessary. This in combination with DFT calculations will provide significant insights into the physical chemical behaviour of metals which will not only benefit fundamental studies but also the design and fabrication of active materials with technological relevance.

\section{Acknowledgements}

AOM gratefully acknowledges funding through a Future Fellowship from the Australian Research Council (FT110100760) and the Asian Office of Aerospace Research and Development (FA2386-13-1-4073).

\section{Notes and references}

1 M. K. Debe, Nature, 2012, 486, 43-51.

2 A. Rabis, P. Rodriguez and T. J. Schmidt, ACS Catal., 2012, 2, 864-890.

3 S. Sharma and B. G. Pollet, J. Power Sources, 2012, 208, 96119.

4 Electrocatalysis in Fuel Cells, a Non- and Low Platinum Approach, ed. M. Shao, Springer, London, 2013.

5 B. J. Plowman, S. K. Bhargava and A. P. O'Mullane, Analyst, 2011, 136, 5107-5119.

6 B. J. Privett, J. H. Shin and M. H. Schoenfisch, Anal. Chem., 2010, 82, 4723-4741.

7 L. Hu and G. Xu, Chem. Soc. Rev., 2010, 39, 3275-3304.
8 G. Ulrich, V. Winfried and Z. Jens, Meas. Sci. Technol., 2009, 20, 042002.

9 J. M. Pingarron, P. Yanez-Sedeno and A. Gonzalez-Cortes, Electrochim. Acta, 2008, 53, 5848-5866.

10 C. Costentin, M. Robert and J.-M. Saveant, Chem. Soc. Rev., 2013, 42, 2423-2436.

11 C. W. Li and M. W. Kanan, J. Am. Chem. Soc., 2012, 134, 7231-7234.

12 R. Reske, M. Duca, M. Oezaslan, K. J. P. Schouten, M. T. M. Koper and P. Strasser, J. Phys. Chem. Lett., 2013, 4, 2410-2413.

13 B. B. Blizanac, P. N. Ross and N. M. Markovic, J. Phys. Chem. $B, 2006,110,4735-4741$.

14 A. S. Bandarenka and M. T. M. Koper, J. Catal., 2013, 308, 11-24.

15 M. T. M. Koper, Nanoscale, 2011, 3, 2054-2073.

16 V. Climent and J. Feliu, J. Solid State Electrochem., 2011, 15, 1297-1315.

17 N. M. Markovica, S. T. Sarraf, H. A. Gasteiger and P. N. Ross, J. Chem. Soc., Faraday Trans., 1996, 92, 3719-3725.

18 R. R. Adžić, S. Strbac and N. Anastasijević, Mater. Chem. Phys., 1989, 22, 349-375.

19 B. E. Hayden, Acc. Chem. Res., 2013, 46, 1858-1866.

20 F. J. Perez-Alonso, D. N. McCarthy, A. Nierhoff, P. Hernandez-Fernandez, C. Strebel, I. E. L. Stephens, J. H. Nielsen and I. Chorkendorff, Angew. Chem., Int. Ed., 2012, 51, 4641-4643.

21 M. Giovanni and M. Pumera, Electroanalysis, 2012, 24, 615617.

22 C. K. Rhee, B.-J. Kim, C. Ham, Y.-J. Kim, K. Song and K. Kwon, Langmuir, 2009, 25, 7140-7147.

23 W. Chen and S. Chen, Angew. Chem., Int. Ed., 2009, 48, 4386-4389.

24 W. Zhou and J. Y. Lee, J. Phys. Chem. C, 2008, 112, 37893793.

25 Y. Kim, H. J. Kim, Y. S. Kim, S. M. Choi, M. H. Seo and W. B. Kim, J. Phys. Chem. C, 2012, 116, 18093-18100.

26 J. Solla-Gullon, F. J. Vidal-Iglesias and J. M. Feliu, Annual Reports Section C, 2011, 107, 263-297.

27 V. Bansal, V. Li, A. P. O'Mullane and S. K. Bhargava, CrystEngComm, 2010, 12, 4280-4286.

28 J. Geng, Y. Bi and G. Lu, Electrochem. Commun., 2009, 11, 1255-1258.

29 H. Zhang, J.-J. Xu and H.-Y. Chen, J. Phys. Chem. C, 2008, 112, 13886-13892.

30 M. Shao, J. Odell, M. Humbert, T. Yu and Y. Xia, J. Phys. Chem. C, 2013, 117, 4172-4180.

31 D. A. Slanac, W. G. Hardin, K. P. Johnston and K. J. Stevenson, J. Am. Chem. Soc., 2012, 134, 9812-9819.

32 M. Tominaga, T. Shimazoe, M. Nagashima and I. Taniguchi, J. Electroanal. Chem., 2008, 615, 51-61.

33 S. Guo, S. Dong and E. Wang, Chem.-Eur. J., 2008, 14, 46894695.

34 A. Balkis and A. P. O'Mullane, Mater. Chem. Phys., 2014, 143, 747-753.

35 L. B. Venarusso, R. H. Sato, P. A. Fiorito and G. Maia, J. Phys. Chem. C, 2013, 117, 7540-7551. 
36 W. Yu, M. D. Porosoff and J. G. Chen, Chem. Rev., 2012, 112, 5780-5817.

37 H. Wang and X. Ge, Electroanalysis, 2012, 24, 911-916.

38 M. Sankar, N. Dimitratos, P. J. Miedziak, P. P. Wells, C. J. Kiely and G. J. Hutchings, Chem. Soc. Rev., 2012, 41, 8099-8139.

39 I. Najdovski, P. R. Selvakannan, S. K. Bhargava and A. P. O'Mullane, Nanoscale, 2012, 4, 6298-6306.

40 S. T. Bliznakov, M. B. Vukmirovic, L. Yang, E. A. Sutter and R. R. Adzic, J. Electrochem. Soc., 2012, 159, F501-F506.

41 S.-M. Hwang, J. E. Bonevich, J. J. Kim and T. P. Moffat, J. Electrochem. Soc., 2011, 158, B1019-B1028.

42 F. J. Vidal-Iglesias, J. Solla-Gullón, E. Herrero, A. Aldaz and J. M. Feliu, Angew. Chem., Int. Ed., 2010, 49, 6998-7001.

43 H. Ataee-Esfahani, L. Wang, Y. Nemoto and Y. Yamauchi, Chem. Mater., 2010, 22, 6310-6318.

44 X. Wang, N. Kariuki, J. T. Vaughey, J. Goodpaster, R. Kumar and D. J. Myers, J. Electrochem. Soc., 2008, 155, B602-B609.

45 K. Klak, D. Marks, A. Wadas, M. Piatek, W. Lotowska, S. Zoladek, I. A. Rutkowska and P. J. Kulesza, ECS Trans., 2013, 45, 13-24.

46 P. J. Kulesza, I. S. Pieta, I. A. Rutkowska, A. Wadas, D. Marks, K. Klak, L. Stobinski and J. A. Cox, Electrochim. Acta, 2013, 110, 474-483.

47 J. Clavilier, R. Faure, G. Guinet and R. Durand, J. Electroanal. Chem. Interfacial Electrochem., 1979, 107, 205-209.

48 J. Clavilier, J. Electroanal. Chem. Interfacial Electrochem., 1979, 107, 211-216.

49 C. A. Lucas and N. M. Marković, in Encyclopedia of Electrochemistry, Wiley-VCH Verlag $\mathrm{GmbH} \&$ Co. KGaA, 2007, DOI: 10.1002/9783527610426.bard020401.

50 N. Hoshi, M. Nakamura and A. Hitotsuyanagi, Electrochim. Acta, 2013, 112, 899-904.

51 N. Tian, Z.-Y. Zhou and S.-G. Sun, J. Phys. Chem. C, 2008, 112, 19801-19817.

52 Z.-Y. Zhou, N. Tian, Z.-Z. Huang, D.-J. Chen and S.-G. Sun, Faraday Discuss., 2009, 140, 81-92.

53 A. Hamelin, J. Electroanal. Chem., 1996, 407, 1-11.

54 A. Hamelin and A. M. Martins, J. Electroanal. Chem., 1996, 407, 13-21.

55 D. M. Kolb and F. C. Simeone, in Scanning Tunneling Microscopy in Surface Science, Nanoscience and Catalysis, ed. M. Bowker and P. R. Davies, WILEY-VCH Verlag GmbH \& Co. KGaA, Weinheim, 2010, pp. 119-146.

56 A. Kuzume, E. Herrero and J. M. Feliu, J. Electroanal. Chem., 2007, 599, 333-343.

57 M. D. Maciá, J. M. Campiña, E. Herrero and J. M. Feliu, J. Electroanal. Chem., 2004, 564, 141-150.

58 J. Solla-Gullon, P. Rodriguez, E. Herrero, A. Aldaz and J. M. Feliu, Phys. Chem. Chem. Phys., 2008, 10, 1359-1373.

59 S. St. John and A. P. Angelopoulos, Electrochim. Acta, 2013, 112, 258-268.

60 L. D. Burke and J. K. Casey, Bull. Electrochem., 1992, 8, 601607.

61 L. D. Burke, J. K. Casey, J. A. Morrissey and M. M. Murphy, Bull. Electrochem., 1991, 7, 506-511.
62 L. D. Burke and D. T. Buckley, J. Electroanal. Chem., 1994, 366, 239-251.

63 L. D. Burke and L. M. Hurley, J. Solid State Electrochem., 2000, 4, 353-362.

64 L. D. Burke and A. P. O'Mullane, J. Solid State Electrochem., 2000, 4, 285-297.

65 L. D. Burke, A. J. Ahern and A. P. O'Mullane, Gold Bull., 2002, 35, 3-10.

66 D. Burke and L. Hurley, J. Solid State Electrochem., 2003, 7, 327-336.

67 S. Garbarino and L. D. Burke, Int. J. Electrochem. Sci., 2010, 5, 828-851.

68 A. J. Ahern, L. C. Nagle and L. D. Burke, J. Solid State Electrochem., 2002, 6, 451-462.

69 L. C. Nagle, A. J. Ahern and L. D. Burke, J. Solid State Electrochem., 2002, 6, 320-330.

70 L. D. Burke, M. J. G. Ahern and T. G. Ryan, J. Electrochem. Soc., 1990, 137, 553-561.

71 L. D. Burke, A. M. O'Connell, R. Sharna and C. A. Buckley, J. Appl. Electrochem., 2006, 36, 919-929.

72 V. Diaz and C. F. Zinola, J. Colloid Interface Sci., 2007, 313, 232-247.

73 V. Díaz, S. Real, E. Téliz, C. F. Zinola and M. E. Martins, Int. J. Hydrogen Energy, 2009, 34, 3519-3530.

74 B. Plowman, S. J. Ippolito, V. Bansal, Y. M. Sabri, A. P. O'Mullane and S. K. Bhargava, Chem. Commun., 2009, 5039-5041.

75 B. J. Plowman, M. Mahajan, A. P. O'Mullane and S. K. Bhargava, Electrochim. Acta, 2010, 55, 8953-8959.

76 B. J. Plowman, A. P. O'Mullane, P. R. Selvakannan and S. K. Bhargava, Chem. Commun., 2010, 46, 9182-9184.

77 B. J. Plowman, A. P. O'Mullane and S. K. Bhargava, Faraday Discuss., 2011, 152, 43-62.

78 B. J. Plowman, I. Najdovski, A. Pearson and A. P. O'Mullane, Faraday Discuss., 2013, 164, 199-218.

79 M. Mahajan, S. K. Bhargava and A. P. O'Mullane, Electrochim. Acta, 2013, 101, 186-195.

80 Y. Wang, E. Laborda, A. Crossley and R. G. Compton, Phys. Chem. Chem. Phys., 2013, 15, 3133-3136.

81 M. A. Schneeweiss, D. M. Kolb, D. Liu and D. Mandler, Can. J. Chem., 1997, 75, 1703-1709.

82 D. M. Kolb, Electrochim. Acta, 2000, 45, 2387-2402.

83 B. Lertanantawong, A. P. O'Mullane, W. Surareungchai, M. Somasundrum, L. D. Burke and A. M. Bond, Langmuir, 2008, 24, 2856-2868.

84 M. J. A. Shiddiky, A. P. O'Mullane, J. Zhang, L. D. Burke and A. M. Bond, Langmuir, 2011, 27, 10302-10311.

85 A. M. Bond, N. W. Duffy, S.-X. Guo, J. Zhang and D. Elton, Anal. Chem., 2005, 77, 186A-195A.

86 J. Zhang, S.-X. Guo, A. M. Bond, M. J. Honeychurch and K. B. Oldham, J. Phys. Chem. B, 2005, 109, 8935-8947.

87 B. J. Plowman, M. R. Field, S. K. Bhargava and A. P. O'Mullane, ChemElectroChem, 2014, 1, 76-82.

88 V. A. Marichev, Russ. J. Electrochem., 1999, 35, 434-440.

89 V. A. Marichev, Surf. Sci. Rep., 2001, 44, 51-158.

90 C. Nguyen Van Huong, C. Hinnen and J. Lecoeur, J. Electroanal. Chem., 1980, 106, 185-191. 
91 Ž. Petrović, M. Metikoš-Huković, R. Babić, J. Katić and M. Milun, J. Electroanal. Chem., 2009, 629, 43-49.

92 J. Rodriguez-Lopez, M. A. Alpuche-Aviles and A. J. Bard, J. Am. Chem. Soc., 2008, 130, 16985.

93 G. Danscher, Histochem. Cell Biol., 2002, 117, 447-452.

94 R. F. Carvalhal, R. Sanches Freire and L. T. Kubota, Electroanalysis, 2005, 17, 1251-1259.

95 A. M. Nowicka, U. Hasse, M. Hermes and F. Scholz, Angew. Chem., Int. Ed., 2010, 49, 1061-1063.

96 A. M. Nowicka, U. Hasse, G. Sievers, M. Donten, Z. Stojek, S. Fletcher and F. Scholz, Angew. Chem., Int. Ed., 2010, 49, 3006-3009.

97 G. Dutta and H. Yang, Electrochem. Commun., 2011, 13, 1328-1331.

98 A. Nowicka, U. Hasse, M. Donten, M. Hermes, Z. Stojek and F. Scholz, J. Solid State Electrochem., 2011, 15, 2141-2147.

99 A. P. O'Mullane and S. K. Bhargava, Electrochem. Commun., 2011, 13, 852-855.

100 S. Cherevko, N. Kulyk and C.-H. Chung, Electrochim. Acta, 2012, 69, 190-196.

101 Z. Wu, Angew. Chem., Int. Ed., 2012, 51, 2934-2938.

102 F. Maillard, F. Gloaguen and J. M. Leger, J. Appl. Electrochem., 2003, 33, 1-8.

103 S. R. Brankovic, J. McBreen and R. R. Adžić, J. Electroanal. Chem., 2001, 503, 99-104.

104 M. S. El-Deab, T. Sotomura and T. Ohsaka, Electrochim. Acta, 2006, 52, 1792-1798.

105 M. S. El-Deab, K. Arihara and T. Ohsaka, J. Electrochem. Soc., 2004, 151, E213-E218.

106 I. Fromondi, H. Zhu and D. A. Scherson, J. Phys. Chem. C, 2012, 116, 19613-19624.

107 M. Watanabe, D. A. Tryk, M. Wakisaka, H. Yano and H. Uchida, Electrochim. Acta, 2012, 84, 187-201.

108 Y. Iwasawa, K. Nagasawa, S. Takao, K. Higashi, S.-i. Nagamatsu, G. Semjeske, Y. Imaizumi, O. Sekizawa, T. Yamamoto and T. Uruga, Phys. Chem. Chem. Phys., 2014, DOI: 10.1039/C3CP54457E.

109 T. Saida, O. Sekizawa, N. Ishiguro, M. Hoshino, K. Uesugi, T. Uruga, S.-i. Ohkoshi, T. Yokoyama and M. Tada, Angew. Chem., Int. Ed., 2012, 51, 10311-10314.

110 N. Ebejer, M. Schnippering, A. W. Colburn, M. A. Edwards and P. R. Unwin, Anal. Chem., 2010, 82, 9141-9145.

111 C. M. Sánchez-Sánchez, J. Solla-Gullón, F. J. Vidal-Iglesias, A. Aldaz, V. Montiel and E. Herrero, J. Am. Chem. Soc., 2010, 132, 5622-5624.

112 J. L. Fernández, D. A. Walsh and A. J. Bard, J. Am. Chem. Soc., 2004, 127, 357-365.

113 S. C. S. Lai, P. V. Dudin, J. V. Macpherson and P. R. Unwin, J. Am. Chem. Soc., 2011, 133, 10744-10747.

114 X. Xiao and A. J. Bard, J. Am. Chem. Soc., 2007, 129, 96109612.

115 X. Xiao, F.-R. F. Fan, J. Zhou and A. J. Bard, J. Am. Chem. Soc., 2008, 130, 16669-16677.

116 X. Xiao, S. Pan, J. S. Jang, F.-R. F. Fan and A. J. Bard, J. Phys. Chem. C, 2009, 113, 14978-14982.

117 Y.-G. Zhou, N. V. Rees, J. Pillay, R. Tshikhudo, S. Vilakazi and R. G. Compton, Chem. Commun., 2012, 48, 224-226.
118 E. J. E. Stuart, Y.-G. Zhou, N. V. Rees and R. G. Compton, RSC Adv., 2012, 2, 6879-6884.

119 S. E. F. Kleijn, S. C. S. Lai, T. S. Miller, A. I. Yanson, M. T. M. Koper and P. R. Unwin, J. Am. Chem. Soc., 2012, 134, 18558-18561.

120 B. D. B. Aaronson, C.-H. Chen, H. Li, M. T. M. Koper, S. C. S. Lai and P. R. Unwin, J. Am. Chem. Soc., 2013, 135, 3873-3880.

121 Z. W. Wang and R. E. Palmer, Nano Lett., 2011, 12, 91-95.

122 K. J. J. Mayrhofer, S. J. Ashton, J. C. Meier, G. K. H. Wiberg, M. Hanzlik and M. Arenz, J. Power Sources, 2008, 185, 734739.

123 K. Hartl, M. Hanzlik and M. Arenz, Energy Environ. Sci., 2011, 4, 234-238.

124 C. Galeano, J. C. Meier, V. Peinecke, H. Bongard, I. Katsounaros, A. A. Topalov, A. Lu, K. J. J. Mayrhofer and F. Schüth, J. Am. Chem. Soc., 2012, 134, 20457-20465.

125 J. Wang, R. M. Asmussen, B. Adams, D. F. Thomas and A. Chen, Chem. Mater., 2009, 21, 1716-1724.

126 A. Tegou, S. Papadimitriou, S. Armyanov, E. Valova, G. Kokkinidis and S. Sotiropoulos, J. Electroanal. Chem., 2008, 623, 187-196.

127 J. Greeley and J. K. Nørskov, Surf. Sci., 2007, 601, 1590-1598.

128 J. Greeley, T. F. Jaramillo, J. Bonde, I. Chorkendorff and J. K. Nørskov, Nat. Mater., 2006, 5, 909-913.

129 J. Greeley, I. E. L. Stephens, A. S. Bondarenko, T. P. Johansson, H. A. Hansen, T. F. Jaramillo, J. Rossmeisl, I. Chorkendorff and J. K. Nørskov, Nat. Chem., 2009, 1, 552-556.

130 V. R. Stamenkovic, B. Fowler, B. S. Mun, G. Wang, P. N. Ross, C. A. Lucas and N. M. Marković, Science, 2007, 315, 493-497.

131 H. A. Hansen, J. B. Varley, A. A. Peterson and J. K. Nørskov, J. Phys. Chem. Lett., 2013, 4, 388-392.

132 A. S. Bandarenka, A. S. Varela, M. Karamad, F. Calle-Vallejo, L. Bech, F. J. Perez-Alonso, J. Rossmeisl, I. E. L. Stephens and I. Chorkendorff, Angew. Chem., Int. Ed., 2012, 51, 11845-11848.

133 G.-F. Wei and Z.-P. Liu, Phys. Chem. Chem. Phys., 2013, 15, 18555-18561.

134 K. Burke, J. Chem. Phys., 2012, 136, 150901-150910.

135 D. F. van der Vliet, C. Wang, D. Tripkovic, D. Strmcnik, X. F. Zhang, M. K. Debe, R. T. Atanasoski, N. M. Markovic and V. R. Stamenkovic, Nat. Mater., 2012, 11, 1051-1058.

136 J. Zhang, H. Yang, J. Fang and S. Zou, Nano Lett., 2010, 10, 638-644.

137 M. Flytzani-Stephanopoulos and B. C. Gates, Annu. Rev. Chem. Biomol. Eng., 2012, 3, 545-574.

138 S. Sun, G. Zhang, N. Gauquelin, N. Chen, J. Zhou, S. Yang, W. Chen, X. Meng, D. Geng, M. N. Banis, R. Li, S. Ye, S. Knights, G. A. Botton, T.-K. Sham and X. Sun, Sci. Rep., 2013, 3, 1-9.

139 J. S. Jirkovský, I. Panas, E. Ahlberg, M. Halasa, S. Romani and D. J. Schiffrin, J. Am. Chem. Soc., 2011, 133, 1943219441.

140 C. E. Banks, A. Crossley, C. Salter, S. J. Wilkins and R. G. Compton, Angew. Chem., Int. Ed., 2006, 45, 2533-2537. 
141 A. Ambrosi and M. Pumera, Nanoscale, 2014, 6, 472-476. 142 C. H. A. Wong, C. K. Chua, B. Khezri, R. D. Webster and M. Pumera, Angew. Chem., Int. Ed., 2013, 52, 8685-8688.

143 A. Ambrosi, C. K. Chua, B. Khezri, Z. Sofer, R. D. Webster and M. Pumera, Proc. Natl. Acad. Sci. U. S. A., 2012, 109, 12899-12904.

144 H. Wang, T. Maiyalagan and X. Wang, ACS Catal., 2012, 2, 781-794.

145 A. Zhao, J. Masa, W. Schuhmann and W. Xia, J. Phys. Chem. C, 2013, 117, 24283-24291.
146 F. Jaouen, E. Proietti, M. Lefevre, R. Chenitz, J.-P. Dodelet, G. Wu, H. T. Chung, C. M. Johnston and P. Zelenay, Energy Environ. Sci., 2011, 4, 114-130.

147 H.-W. Liang, W. Wei, Z.-S. Wu, X. Feng and K. Müllen, J. Am. Chem. Soc., 2013, 135, 16002-16005.

148 X. Zhang, J. Guo, P. Guan, C. Liu, H. Huang, F. Xue, X. Dong, S. J. Pennycook and M. F. Chisholm, Nat. Commun., 2013, 4, DOI: 10.1038/ncomms2929.

149 F. Calle-Vallejo, J. I. Martínez, J. M. García-Lastra, E. Abad and M. T. M. Koper, Surf. Sci., 2013, 607, 47-53. 